\title{
High dose intravenous streptokinase in acute myocardial infarction-short and long term prognosis
}

\author{
B a MaclenNaN, A McMASTER, S W WEBB, M M KHAN, A A J ADGEY \\ From the Regional Medical Cardiology Centre, Royal Victoria Hospital, Belfast, Northern Ireland
}

SUMMARY Streptokinase ( 1 million international units) was given intravenously over 30 or 60 minutes to 50 patients four hours or less after the onset of acute myocardial infarction. All were aged $\leqslant 70$ years and had $4 \mathrm{~mm}$ or greater ST segment elevation in anterior or inferior leads. Rapid (mean $95 \mathrm{~min}$ ) ST segment resolution, which was taken to indicate reperfusion of the myocardium, occurred in $36(72 \%)$ patients. In these 36 the average time from onset of symptoms to peak creatine kinase, creatine kinase $\mathrm{MB}$, and myoglobin was 9.45 hours, whereas it was 17 hours in the 14 patients in whom indirect criteria did not indicate reperfusion. Reperfusion arrhythmias were invariably present and ventricular tachycardia developed in five patients and ventricular fibrillation in two. The infarct related artery was seen to be open in $28(70 \%)$ of the 40 patients who had delayed coronary arteriography. The frequency of patency in the infarct related artery was no different in patients given streptokinase $<2$ hours or between $2-4$ hours from onset of symptoms nor did it differ when streptokinase was infused over 30 or 60 minutes. Mean left ventricular ejection fraction was $57 \%$ in those with a patent infarct related artery and $48 \%$ in those with an occluded vessel. Eight patients subsequently underwent elective percutaneous transluminal coronary angioplasty after successful thrombolysis and six had coronary artery bypass grafting. There were nine in-hospital reocclusions of the infarct related coronary arteries. Two bleeding episodes occurred; one required transfusion. Five of the 50 patients died in hospital. All of them had had an anterior myocardial infarction; four had bifascicular block and one had right bundle branch block. During follow up, four patients died, two suddenly and two from reinfarction. During follow up (mean 15 months) the frequency of reinfarction, dyspnoea, and angina was low and there was no difference in the proportions of patients returning to work between those with an open infarct related artery and those with a closed infarct related artery.

Intravenous administration of high dose streptokinase to selected patients during the acute phase of myocardial infarction is a safe, effective, and practical method of thrombolysis. It must, however, be followed by coronary arteriography to select those patients in whom percutaneous transluminal coronary angioplasty or coronary artery bypass grafting will be helpful.

In most patients acute myocardial infarction is associated with an acute intraluminal coronary artery thrombosis on an atheromatous plaque. ${ }^{1-4}$ The amount of necrotic muscle resulting from coronary artery occlusion is a major factor determining the

Requests for reprints to Dr A A J Adgey, Regional Medical Cardiology Centre, Royal Victoria Hospital, Belfast BT12 6BA, Northern Ireland.

Accepted for publication 3 December 1985 outcome of acute myocardial infarction. Although recanalisation of a coronary artery may occur spontaneously, ${ }^{5}$ restoration of anterograde flow in the occluded vessel by thrombolytic treatment may terminate or limit the ischaemic process and so reduce the amount of tissue death. At present, early reopening of an occluded infarct related vessel by thrombolysis appears to be the most promising approach in limiting infarct size. ${ }^{6}$

During acute infarction the area of acute necrosis 
spreads from the subendocardial surface through to the subepicardial surface, ${ }^{78}$ and experimental studies in dogs have shown that early interruption of this destructive advance is likely to offer the best prospect of salvage or recovery in the ischaemic myocardium. ${ }^{910}$ Establishing reperfusion within four hours of complete ischaemia may result in important structural and functional recovery. ${ }^{112}$ After four hours of complete ischaemia major improvement seems to be unlikely ${ }^{1112}$ and reperfusion in such cases possibly only helps to accelerate the decay of already irreversibly injured tissue. The extent of collateral flow, however, is likely to be a major determinant of the time course and final size of infarction in patients. ${ }^{8}$

Despite almost two decades of experience, the benefits and risks of administration of intravenous streptokinase in acute myocardial infarction remain to be established. Early randomised studies ${ }^{13-15}$ gave equivocal results because populations were heterogenous, treatment was started too late (6-12 hours or more) after the onset of symptoms to be of any benefit, slower infusion times were used, and evidence of reperfusion was not recognised or was misinterpreted.

Intracoronary streptokinase given on average (SD) 4.3(1.4) hours after acute myocardial infarction was associated with a $76 \%$ recanalisation rate in the infarct related artery. ${ }^{16}$ When intravenous streptokinase was given on average $2 \cdot 8(1)$ hours after onset of symptoms, the same workers showed a recanalisation rate of $73 \% .{ }^{16}$ When intravenous streptokinase was given within six hours of myocardial infarction, early reperfusion, that is within one hour, occurred in $49 \%$ of patients. ${ }^{17}$ In a similar group of patients Schroder found a patent infarct related artery in $84 \%$ at angiography four weeks later. ${ }^{18}$ The intravenous route, which does not require emergency arteriography and so is more generally applicable, allows treatment to be started as soon as possible after the onset of symptoms.

We have evaluated the effects of high dose short term intravenous streptokinase in patients presenting within four hours of the onset of acute myocardial infarction and have followed their course after leaving hospital.

\section{Patients and methods}

All patients were aged $\leqslant 70$ years, had had symptoms for $\leqslant 4$ hours, and showed an acute injury pattern on the electrocardiogram (that is $\geqslant 4 \mathrm{~mm} \mathrm{ST}$ segment elevation in two or more anterior or inferior electrocardiographic leads after pain relief). No patient had uncontrolled hypertension or a potential bleeding site. Those patients already on anti- coagulants were excluded. Informed consent was obtained from all. No patient died between acceptance for the study and the administration of streptokinase.

Before treatment was started, blood was drawn for a complete blood count, platelet count, prothrombin time, partial thromboplastin time, fibrinogen, total creatine kinase, creatine kinase- $\mathrm{MB}$, and myoglobin. A 12 lead electrocardiogram was recorded. Hydrocortisone $(250 \mathrm{mg})$, given intravenously to prevent an allergic reaction to streptokinase, was followed immediately by a 100000 IU bolus of streptokinase and then by an infusion of $900000 \mathrm{IU}$ in $100 \mathrm{ml}$ of physiological saline. Infusion lasted 60 minutes in $20(40 \%)$ patients and over 30 minutes in $30(60 \%)$ patients. After the streptokinase infusion, heparin 40000 IU was infused over 24 hours. The activated partial thromboplastin time was checked at two, four, eight, 12, and 24 hours after completion of streptokinase administration and the amount of heparin infused was adjusted daily in an attempt to maintain the activated partial thromboplastin time between 80 and $120 \mathrm{~s}$. The infusion of heparin was continued until either delayed coronary arteriography was performed or circumstances dictated otherwise. After arteriography, if angioplasty was not considered, heparin was discontinued and either antiplatelet drugs or warfarin were given daily. After the end of the streptokinase infusion the electrocardiogram was recorded again and thereafter at 30 minutes, one, two, four, eight, 12, 16, and 24 hours with concurrent measurement of serum creatine kinase, creatine kinase-MB, and myoglobin concentrations. Thereafter electrocardiograms were recorded daily. Coronary arteriography was performed later by the Judkins's transfemoral technique in all except one patient in whom the brachial approach was used. Ejection fraction was assessed in the $30^{\circ}$ right anterior oblique projection of the left ventriculogram.

Reperfusion of the myocardium or recanalisation of a recently occluded artery was recognised by $(a)$ rapid decline ( $\geqslant 3 \mathrm{~mm}$ ) of the $S T$ segment injury current on the electrocardiogram; $(b)$ early rise and peak ( $\leqslant 12$ hours) in serum creatine kinase, creatine kinase-MB, and myoglobin levels; (c) the occurrence of specific reperfusion arrhythmias-ventricular extrasystoles, runs of idioventricular rhythm, ventricular tachycardia, or ventricular fibrillation; $(d)$ luminal patency of infarct related artery demonstrated at coronary arteriography.

\section{Results}

Thrombolysis was attempted in 50 patients $(41$ male and nine female) aged 37-69 (mean 57 years); 33 of 
Table 1 Peak creatine kinase (CK), creatine kinase- $M B(C K-M B)$, and myoglobin $(M B)$ and time taken to reach peak values in patients with an open infarct related artery and those with a closed artery

\begin{tabular}{|c|c|}
\hline Peak mean ( $S D)$ & Time to peak $(h)^{\star}$ \\
\hline $\begin{array}{l}\text { Open artery: } \\
\text { CK 2337 (1580) U/1 } \\
\text { CK-MB 121 (88) U/1 } \\
\text { MB 2613(3060) } \mu \mathrm{g} / 1\end{array}$ & $\begin{array}{l}4-12(8 \cdot 5) \\
3-10(7 \cdot 45) \\
3-8(6.5)\end{array}$ \\
\hline $\begin{array}{l}\text { Closed artery: } \\
\text { CK 2105 (506) U/1 } \\
\text { CK-MB } 87(43) U / 1 \\
\text { MB 2664 (1936) } \mu \mathrm{g} / 1\end{array}$ & $\begin{array}{l}9-24(16) \\
7-18(15) \\
6-13(8)\end{array}$ \\
\hline
\end{tabular}

^Range (mean).

them had had an anterior infarction and 17 had had an inferior infarction. Nine had had previous myocardial infarctions. Streptokinase was administered on average 150 (range 35-240 $\mathrm{min}$ ) after the onset of symptoms. Of the 50 patients, $36(72 \%)$ showed indirect evidence of reperfusion. Rapid resolution of ST injury pattern by $\geqslant 3 \mathrm{~mm}$ occurred in all 36 in an average time of $95 \mathrm{~min}$ (range 30-180 $\mathrm{min}$ ) after the start of treatment. Serum creatine kinase, creatine kinase-MB, and myoglobin kinetics were accelerated in all those who showed ST segment improvement. Peak values were reached $\leqslant 12$ hours (mean 9.45 hours, range 3-12 hours) after onset of symptoms in the 36 patients showing rapid ST segment resolution. In those whose ST segments remained elevated $(\geqslant 4 \mathrm{~mm}$ ) creatine kinase, creatine kinase-MB, and myoglobin values reached a peak 17.3 hours (range 6-24 hours) after the onset of symptoms. In these 14 patients indirect criteria were considered not to indicate reperfusion.

Forty patients, 25 with anterior infarction and 15 with inferior infarction, subsequently underwent delayed coronary arteriography. Of the 10 patients who did not undergo coronary arteriography, five had died in hospital, three had had overt reinfarctions with further chest pain, ST segment reelevation, and a further rise in serum enzyme activity, and two showed evidence of initial large infarctions without indirect evidence of reperfusion.
Thirty five patients underwent arteriography within 21 days (mean 14, range 6-21 days), four patients between 22-28 days, and one at one month after admission (this patient had developed a retroperitoneal haematoma during the initial hospital admission). Single vessel disease with $\geqslant 70 \%$ stenosis was present in $18(45 \%)$ patients, double vessel disease in $11(27 \%)$, and triple vessel disease in six $(15 \%)$. The remaining five had lesions with $<70 \%$ stenosis. The artery supplying the infarct territory was patent in $14(78 \%)$ of the 18 patients with single vessel disease, in six $(54 \%)$ of the 11 patients with double, and in three $(50 \%)$ of the six patients with important triple vessel disease. Eighteen had been given streptokinase over 60 minutes and in $11(61 \%)$ of them the infarct related artery was open. Twenty two patients had streptokinase administered over 30 minutes and $17(77 \%)$ of them had an open infarct related artery. These differences were not statistically significant.

Thus the infarct related artery was patent in 28 $(70 \%)$ patients. Of these 28 open arteries, $19(68 \%)$ were associated with anterior infarction and nine $(32 \%)$ with inferior infarction. Concordance between direct and indirect evidence of reperfusion was very high: all patients whose myocardium was reperfused (that is had an open infarct related artery) had one or more reperfusion arrhythmias and in all except two serum enzymes peaked within 12 hours of the onset of symptoms. Enzyme release and the time to peak enzyme activities for those with an open infarct related artery were compared with values in patients with a closed infarct related artery (Table 1). There was no statistically significant difference between those with open and closed infarct related arteries for mean peak creatine kinase, creatine kinase- $\mathrm{MB}$, or myoglobin. Time to peak creatine kinase, creatine kinase-MB, and myoglobin from onset of symptoms was earlier, however, in the group with the open infarct related artery than in the group with a closed infarct related artery. Eighteen patients received streptokinase within two hours of the onset of symptoms and in $13(72 \%)$ of them the

Table 2 Details of patients with re-occlusion

\begin{tabular}{|c|c|c|c|c|}
\hline Patient No & $\begin{array}{l}\text { Initial and reinfarction } \\
\text { sites }\end{array}$ & $\begin{array}{l}A P T T \text { at time of } \\
\text { reocclusion (s) }\end{array}$ & Time of reocclusion & $\begin{array}{l}\text { Angiography } \\
\text { (infarct related artery) }\end{array}$ \\
\hline $\begin{array}{l}1 \\
2 \\
3 \\
4 \\
5 \\
6 \\
7 \\
8 \\
9\end{array}$ & $\begin{array}{l}\text { Anterior } \\
\text { Inferior } \\
\text { Inferior } \\
\text { Inferior } \\
\text { Inferior } \\
\text { Anterior } \\
\text { Anterior } \\
\text { Anterior } \\
\text { Anterior }\end{array}$ & $\begin{array}{l}\overline{45} \\
60 \\
\frac{58}{27} \\
\frac{45}{34}\end{array}$ & $\begin{array}{l}\text { Silent } \\
\text { Day } 3 \\
\text { Day } 4 \\
\text { Day } 9 \\
\text { Silent } \\
\text { Day } 4 \\
\text { Silent } \\
\text { Day } 5 \\
\text { Day } 5\end{array}$ & $\begin{array}{l}100 \% \text { occluded } \\
\text { No angiogram } \\
\text { No angiogram } \\
100 \% \text { occluded } \\
100 \% \text { occluded } \\
100 \% \text { occluded } \\
100 \% \text { occluded } \\
\text { No angiogram } \\
100 \% \text { occluded }\end{array}$ \\
\hline
\end{tabular}

APTT, activated partial thromboplastin time. 
infarct related artery was open. Twenty two received streptokinase between two and four hours after the onset of symptoms and in $15(68 \%)$ the infarct related artery was open. Eleven had received streptokinase infusion over $60 \mathrm{~min}$ and 17 over $30 \mathrm{~min}$.

Left ventricular ejection fraction at angiography was on average $57 \%$ (range $23-84 \%$ ) in those with patent lumens and $48 \%$ (range $27-71 \%$ ) in those with an occluded infarct related artery. This difference is not statistically significant. The ejection fractions were independent of the timing - that is whether arteriography was performed within or more than two weeks after treatment. In those who had reperfusion of the myocardium the average ejection fraction associated with inferior infarction was $64 \%$, whereas in those with anterior infarction it was $57 \%$.

Six $(12 \%)$ of the 50 patients had had ventricular fibrillation before streptokinase administration. Five of these showed indirect evidence of reperfusion and two had open infarct related arteries at arteriography. Three had overt reinfarctions, and at arteriography in two the infarct related artery was closed. The sixth patient died in hospital. Early postthrombolytic or reperfusion arrhythmiasidioventricular rhythm and late diastolic ventricular ectopic beats-were invariably present in patients with reperfusion of the myocardium. Five $(10 \%)$ had ventricular tachycardia within four hours of streptokinase infusion, which required antiarrhythmic treatment, and in all of them the infarct related artery was patent at angiography. Two patients had ventricular fibrillation within five hours of streptokinase (one had had it before treatment and later died in pump failure; in the second, the infarct related artery was patent at arteriography).

Six overt non-fatal reinfarctions with chest pain, ST segment elevation, and increases in serum enzymes occurred in hospital (Table 2). Three of these patients subsequently underwent arteriography and in all of them the infarct related artery was occluded. Three patients who had shown indirect evidence of reperfusion had occlusion of the infarct related ar- tery at angiography (considered to be silent reinfarction) and all survived. Thus nine (18\%) reocclusions (five anterior, four inferior) occurred in hospital. No patient received further streptokinase after initial treatment.

None of the patients appeared to be allergic to streptokinase. Two bleeding events occurred. One 69 year old woman had gingival oozing within two hours of streptokinase infusion. Activated partial thromboplastin time was $65 \mathrm{~s}$. Heparin dosage was subsequently halved, but she had a reinfarction on the third hospital day when the activated partial thromboplastin time was $45 \mathrm{~s}$. No blood transfusion was required. A 47 year old man developed a retroperitoneal haematoma on day nine after streptokinase and while he was on heparin infusion and his activated partial thromboplastin time was $120 \mathrm{~s}$. Five units of blood were transfused.

Eight patients who had successful reperfusion of the myocardium had elective percutaneous transluminal coronary angioplasty because they had stenoses accessible to this technique. Two of these patients had single vessel disease, three had double vessel disease, and three had triple vessel disease. Angioplasty was only used for single lesions-four right coronary artery lesions of between $90 \%$ and $99 \%$ and four left anterior descending lesions of between $85 \%$ and $95 \%$ narrowing. Coronary artery bypass grafting was carried out in patients with high grade lesions who continued to have angina despite intensive medical treatment. Six patients underwent coronary artery bypass grafting-four had single vessel disease (70-90\% narrowing), one double vessel disease $(100 \%$ and $95 \%)$, and one triple vessel disease $(95 \%, 100 \%, 95 \%$ lesions).

There were five $(10 \%)$ in-hospital deaths (Table 3). All the patients had anterior infarction and three had had previous inferior infarctions (average age 60 years, range 43-69). The mean duration of symptoms before streptokinase administration was 136 min (range 120-160). On admission four had bifascicular block and one right bundle branch block and four had pulmonary oedema. None had indirect

Table 3 Details of the patients who died in hospital

\begin{tabular}{llllll}
\hline Patient No & Sex/Age & Site of infarction & $\begin{array}{l}\text { Conduction } \\
\text { abnormality }\end{array}$ & $\begin{array}{l}\text { Time from } \\
\text { admission to death }\end{array}$ & $\begin{array}{l}\text { Pulmonary oedema } \\
\text { on admission }\end{array}$ \\
\hline 1 & Male, 68 & Anterior & RBBB + LAH & $33 \mathrm{~h}$ & + \\
2 & Female, 69 & $\begin{array}{c}\text { Anterior } \\
\text { (old inferior) }\end{array}$ & RBBB & 21 days & + \\
3 & Male, 54 & $\begin{array}{c}\text { Anterior } \\
\text { (old inferior) }\end{array}$ & RBBB + RPH & $4 \mathrm{~h}$ & 0 \\
4 & Male, 68 & $\begin{array}{c}\text { Anterior } \\
\text { (old inferior) }\end{array}$ & RBBB + LAH & $3 \mathrm{~h}$ & + \\
5 & Male, 43 & Anterior & RBBB + LAH & $5 \mathrm{~h}$ & + \\
\hline
\end{tabular}

RBBB, right bundle branch block; LAH, left anterior hemiblock; RPH, right posterior hemiblock. 
evidence of reperfusion nor did the conduction delay resolve in any after streptokinase; none had streptokinase antibodies since in all five serum fibrinogen fell significantly. None of these patients underwent coronary arteriography. Death occurred in three, four, five, 33 hours, and on day 21 after admission. All were in cardiogenic shock before death. Three necropsies were performed. Two patients had severe triple vessel disease (stenosing atheroma) with recent thrombi in the infarct related vessels, and the third patient had single vessel disease with a recent total occlusion of the infarct related artery (Interstitial oedema was present in the lungs in all three. Fibrosis and scarring of the inferior and posterior surfaces of the left ventricle was noted in two patients in keeping with previous infarction.)

Of the 45 patients who were discharged, 40 had had angiography. Excluding the 11 who had either percutaneous transluminal coronary angioplasty or coronary artery bypass grafting or both, important stenoses were found in 15 of the remaining 29 patients with single vessel disease, in seven with double vessel disease, and in three with triple vessel disease. The remaining four patients had $<70 \%$ stenosis of one or more vessels. Six of the 15 patients with single vessel disease had $70-79 \%$ lesions and nine patients had $90-100 \%$ lesions; in 10 of these patients they were left anterior descending coronary artery lesions and in five patients they were right coronary artery lesions. Of the seven with double vessel disease, three had $70-79 \%$ and four had 90-100\% lesions of the left anterior descending artery; six had narrowing of the right coronary artery (in one this was $70-79 \%$, in another it was $80-89 \%$, and in four it ranged from $90 \%$ to $100 \%$ ); and one patient had $70 \%$ narrowing of the circumflex artery. All three with triple vessel disease had $90-100 \%$ narrowing of the left anterior descending artery and in all of them the right coronary artery was occluded; in three patents the circumflex artery was narrowed (70\% in one and $90-95 \%$ in two).

Of the $\mathbf{4 5}$ patients discharged from hospital, 28 had an open infarct related artery at angiography and two of these died during follow up; 12 had a closed infarct related artery and two of these died during follow up. None of the five who did not have coronary angiography died. Of the four deaths, one patient, a 58 year old man, died suddenly at home 10 months after discharge. He had had an earlier myocardial infarction before the one during which streptokinase was given. At angiography he had single vessel disease with an occluded infarct related artery. A treadmill exercise test was not performed because his left ventricular ejection fraction was only $10 \%$. He had no angina after leaving hospital and was being treated for congestive heart failure. The second patient was a man aged 57 years who also died suddenly at home 12 months after discharge. The predischarge angiogram showed double vessel disease $(100 \%$ and $75 \%$ lesions $)$ with a closed infarct related coronary artery. This patient achieved 10 minutes of exercise on the Naughton and Balke protocol. He did not have chest pain during the exercise treadmill test nor did the blood pressure drop or any arrhythmias develop. ST segment elevation occurred in the area of inferior infarction and there were reciprocal changes in the anterior leads. He had not had angina after discharge. Case 3 was a 52 year old man who died from a further infarction 10 months after discharge. At angiography he had single vessel disease with $80 \%$ narrowing. He had been symptom free, had had no treadmill exercise stress test, and no angina had occurred after discharge. Case 4 was a 47 year old man who died of left ventricular failure associated with a further infarction three months after discharge. Reinfarction occurred during a treadmill exercise stress test and the patient died despite emergency bypass operation. At previous angiography he had $95 \%$ narrowing of left anterior descending artery (open infarct related artery), the right coronary artery was occluded, and there was $99 \%$ narrowing in the circumflex artery. The patient had claimed to be symptom free. Only two patients had reinfarctions during follow up and both of them died.

During the 11-22 months (mean 15.5 months) of follow up 11 of the remaining 41 patients had angina (New York Heart Association grade I or grade II). Eight of those with angina (grade I) had an open infarct related artery on discharge. Of the remaining three, two had a closed infarct related artery on discharge and in one there was no predischarge angiogram. Of these 11 patients, six had single vessel disease with $\geqslant 70 \%$ stenosis, one had double vessel

Table 4 Drug treatment of the 41 patients during follow up

\begin{tabular}{llllll}
\hline & $\begin{array}{l}\text { Calcium } \\
\text { antagonists }\end{array}$ & Nitrates & $\beta$ blockers & $\begin{array}{l}\text { Antiplatelet } \\
\text { agents }\end{array}$ & Anticoagulants \\
\hline $\begin{array}{l}\text { Open infarct related artery on } \\
\text { discharge (26 cases) }\end{array}$ & 15 & 17 & 11 & 15 & 5 \\
$\begin{array}{c}\text { Closed infarct related artery } \\
(10 \text { cases) or no angiogram }\end{array}$ & 5 & 4 & 4 & 4 & 1 \\
$\quad(5$ cases) & & & & & \\
\hline
\end{tabular}


disease with $\geqslant 70 \%$ stenosis, one had double vessel disease, and two had triple vessel disease. One patient had a single vessel $50 \%$ stenosis and one had no angiogram. Thirty eight patients had no dyspnoea. Two patients were in New York Heart Association functional class I and one was in functional class II. Table 4 shows the drugs taken during follow up.

Fifteen of the 41 patients went back to full employment, 14 retired early, nine remained unemployed, and three became unemployed. There was no difference in the proportions of those going back to work between those in whom the infarct related artery was open and those in whom it was closed.

\section{Discussion}

Experience with patients undergoing thrombolytic treatment with intracoronary streptokinase suggests that the infarct related artery is likely to be occluded in $80-90 \%$ of patients before treatment is started. ${ }^{19}$ The major findings in our study were that intravenous high dose streptokinase is a quick, safe, and effective method of achieving thrombolysis in selected patients during the acute phase of myocardial infarction and that $70 \%$ of infarct related arteries were patent at angiography. These results compare favourably with other studies in which successful coronary artery recanalisation was achieved in about $75 \%$ of patients with myocardial infarction treated by intracoronary streptokinase. ${ }^{20}$ Alderman et al in a randomised study of patients with myocardial infarction gave streptokinase within 3.5 hours of the onset of symptoms; the patency rate with intravenous administraton was $62 \%$ compared with $73 \%$ in those receiving it by the intracoronary route. ${ }^{21}$ Mayer et al found that high dose intravenous streptokinase given an average of $2.77(1.31)$ hours from the onset of symptoms gave a patency rate of $83 \%$ in the infarct related artery at follow up angiography. ${ }^{22}$

Delay, the critical issue determining successful outcome, is minimised by intravenous administration which has the advantage of earlier and easier application in virtually every medical care facility. All our patients had had symptoms for four hours or less and the successful outcome of treatment in those treated within two hours of onset of symptoms $(72 \%)$ compared favourably with those who were treated after two hours $(68 \%)$. Thus it would seem reasonable to administer streptokinase to patients within four hours of the onset of acute myocardial infarction when it is still possible to achieve successful thrombolysis. The shorter streptokinase infusion time of 30 minutes vs 60 minutes was not associated with a significant increase in achieving patency of the infarct related artery $(77 \%$ vs $61 \%)$.
Although the groups were too small to determine the statistical significance of any differences, it was our impression that thrombolysis was more effective in patients with single vessel than in those with double or triple vessel disease $(78 \%$ vs $54 \%$ vs $50 \%)$. Many of these single vessel lesions are accessible to subsequent angioplasty. The occurrence of ventricular fibrillation before thrombolysis should not deter one from attempting to interrupt the natural evolution to complete infarction. Two of the six patients in this study who had ventricular fibrillation before treatment later showed successful recanalisation. In one the rhythm disturbance recurred during treatment. Nevertheless, if human ventricular fibrillation resembles animal ventricular fibrillation then the longer the interval before reperfusion of an occluded vessel is established the less likely is ventricular fibrillation to develop. ${ }^{7}$ Five patients developed ventricular tachycardia within four hours of thrombolysis. All were treated with conventional antiarrhythmic agents, in none was the arrhythmia fatal, and in all the infarct related artery was patent on angiography. These results indicate that prehospital administration of streptokinase in acute infarction should be considered, so that delay may be avoided and reperfusion be achieved as early as possible. Certainly the potential development of serious ventricular arrhythmias outside hospital should not exclude this therapeutic option.

In this study indirect evidence of reperfusion as demonstrated by accelerated electrocardiographic evolution and peak serum enzyme kinetics correlated well with the subsequent angiographic verification of patency. Both these non-invasive variables are now recognised markers of reperfusion. ${ }^{1618192324}$ When they occurred with reperfusion arrhythmias (late diastolic ventricular premature beats and self-terminating idioventricular rhythm $^{25}$ ) recanalisation of the infarct related artery was almost always found. This information is most useful when facilities for performing coronary angiography are not available, and a clinical decision on which patients should be referred to specialised centres for arteriography after thrombolysis has to be made.

Ventricular function is often used to gauge success after thrombolysis. None the less ejection fractions must be considered with caution because the assessment of left ventricular function immediately after reperfusion is unlikely to demonstrate the ultimate benefit of thrombolysis as myocardial stunning may take place early on. ${ }^{12}$ Left ventricular function (as measured by ejection fraction) is less severely impaired after inferior infarction than after anterior infarction in patients not receiving thrombolytic agents. ${ }^{26}$ In this study the average ejection fraction 
for those with inferior infarction was higher than that for patients with anterior infarction. In a randomised study by Khaja et al of intracoronary streptokinase $v s$ placebo given within six hours of acute myocardial infarction no beneficial effect on left ventricular function was seen, ${ }^{27}$ unlike the results of the randomised study reported by Anderson et al in which ventricular performance was significantly better in those receiving intravenous streptokinase at $2 \cdot 8(1)$ (mean (SD)) hours than in a historical control group. ${ }^{16}$ In our study left ventricular ejection fraction averaged $57 \%$ in those where the infarct related artery successfully recanalised after treatment and $48 \%$ in those with artery occlusion at angiography. Although this difference was not statistically significant, the improvement of approximately $10 \%$ in ejection fraction recorded in our study in successfully treated patients accords with reports from other workers. ${ }^{11}$ Improved ventricular performance leads to better long term survival. Fatal arrhythmias and pump failure are more likely to develop in patients with low ejection fractions after acute myocardial infarction. ${ }^{26}$

Vessels with residual stenotic cross sectional areas less than $0.4 \mathrm{~mm}^{2}$ are at high risk for rethrombosis, whereas vessels with minimal cross sectional areas of $>0.4 \mathrm{~mm}^{2}$ are unlikely to develop rethrombosis. ${ }^{28}$ Harrison et al found that $50 \%$ of patients with residual lesions causing $>90 \%$ area stenosis had reocclusion whereas no patient with lesions of $<90 \%$ area stenosis had vessel reocclusion. ${ }^{28}$ After streptokinase reperfusion, however, the residual size of the lumen may change over the subsequent days either because of resolution of coronary artery spasm or lysis of persistent thrombi or changes in the atheromatous plaque. The reocclusion rate in this study was $18 \%$ (nine of 50 ). In most, anticoagulation at the time of reocclusion was considered to be suboptimal or was proving difficult to control. In three of the nine patients indirect criteria suggested recanalisation; this was followed by reocclusion. This has been described by others. ${ }^{29} 30$ Successful thrombolysis will not alter the underlying disease process and the tendency to rethrombosis is a great and an ever present risk. ${ }^{31} 32$ With anticoagulation, however, the reocclusion risk is likely to be low. The interval coronary arteriogram should be performed as early as possible after thrombolytic intervention, however. None the less this does not imply that the longer the delay in performing coronary arteriography, the greater the likelihood of rethrombosis. Reocclusion in our series occurred throughout the post-thrombolytic in-hospital period as did arteriography. In many cases the results of coronary arteriography will dictate the further management in the short or intermediate term. ${ }^{33}{ }^{34} \mathrm{Per}$ - cutaneous transluminal coronary angioplasty was performed in eight patients who had lesions accessible to this technique in an attempt to optimise initial therapeutic success and preserve vascular patency. Six underwent coronary artery bypass operation because they had high grade lesions with continuing angina despite intensive medical treatment.

Bleeding complications during the study were infrequent. One patient required a blood transfusion for a retroperitoneal haematoma, which was caused by the heparin infusion rather than streptokinase. No allergic manifestations were seen in response to streptokinase. Five $(10 \%)$ patients died during hospital stay. All were in the high risk group-that is they all had anterior infarctions, three had had previous inferior infarctions, four had pump failure on admission, and all had conduction abnormalities which were not corrected after streptokinase infusion. None of these patients showed indirect evidence of reperfusion. All were in cardiogenic shock at the time of death, with pump failure and a terminal arrhythmia. Thus the adverse prognosis, well recognised in this particular group of patients, was not improved by attempted thrombolysis.

Four of the 45 patients who survived to leave hospital died (two suddenly, two reinfarction) during follow up. The mortality rate was not higher than expected. For the remaining 41 patients, follow up lasted 11-22 months (average 15.5 months). Anticoagulation should continue outside hospital in this group of patients, particularly in those with high grade lesions. During the follow up the incidence of reinfarction, angina, and dyspnoea was low, as has been found by other workers. ${ }^{17}$ The proportion of those with an open infarct related artery who went back to work was no different from that in those with a closed infarct related artery.

Intravenous streptokinase administration in early myocardial infarction appears to be a promising, safe, and effective treatment which can be used by all medical intensive care facilities. In our patients modification of the early course by successful thrombolysis meant that other measures to preserve vascular patency could subsequently be used during acute hospital stay and follow up. Successful thrombolysis will not modify the underlying coronary artery disease, and streptokinase should not be viewed as a therapeutic "magic bullet"; adjuvant treatment with agents designed to assist in myocardial salvage are currently being explored as are second generation fibrin-specific thrombolytic enzymes such as anisoylated plasminogen-streptokinase complex (BRL 26921) ${ }^{35}$ or recombinant tissue type plasminogen activator. ${ }^{36-41}$ 


\section{References}

1 Silver MD, Baroldi G, Mariani F. The relationship between acute occlusive coronary thrombi and myocardial infarction studied in 100 consecutive patients. Circulation 1980; 61: 219-27.

2 DeWood MA, Spores J, Notske R, et al. Prevalence of total coronary occlusion during the early hours of transmural myocardial infarction. $N$ Engl f Med 1980; 303: 897-902.

3 Weinstein J. The international registry to support approval of intracoronary streptokinase thrombolysis in the treatment of myocardial infarction. Assessment of safety and efficacy. Circulation 1983; 68(suppl I): 61-6.

4 Bertrand ME, Lefebvre JM, Laisne CL, Rousseau MF, Carre AG, Lekieffre JP. Coronary arteriography in acute transmural myocardial infarction. Am Heart $\mathcal{F}$ 1979; 97: 61-9.

5 Ong L, Reiser P, Coromilas J, Scherr L, Morrison J. Left ventricular function and rapid release of creatine kinase $\mathrm{MB}$ in acute myocardial infarction. Evidence for spontaneous reperfusion. $N$ Engl f Med 1983; 309: 1-6.

6 Markis JE, Malagold M, Parker JA, et al. Myocardial salvage after intracoronary thrombolysis with streptokinase in acute myocardial infarction. Assessment by intracoronary thallium-201. N Engl f Med 1981; 305: 777-82.

7 Reimer KA, Lowe JE, Rasmussen MM, Jennings RB. The wavefront phenomenon of ischaemic cell death. 1 Myocardial infarct size vs duration of coronary occlusion in dogs. Circulation 1977; 56: 786-93.

8 Jennings RB, Reimer KA. Factors involved in salvaging ischaemic myocardium; effect of reperfusion of arterial blood. Circulation 1983; 68(suppl I): I 25-36.

9 Bush LR, Buja LM, Samowitz W, et al. Recovery of left ventricular segmental function after long-term reperfusion following temporary coronary occlusion in conscious dogs. Comparison of 2 and 4 hour occlusions. Circ Res 1983; 53: 248-63.

10 Lavallee M, Cox D, Patrick TA, Vatner SF. Salvage of myocardial function by coronary artery reperfusion 1,2 and 3 hours after occlusion in conscious dogs. Circ Res 1983; 53: 235-47.

11 Schwarz F, Schuler G, Katus H, et al. Intracoronary thrombolysis in acute myocardial infarction: duration of ischaemia as a major determinant of late results after recanalisation. Am $\mathcal{F}$ Cardiol 1982; 50: 933-7.

12 Laffel GL, Braunwald E. Thrombolytic therapy. A new strategy for the treatment of acute myocardial infarction (first of two parts). $N$ Engl $\mathcal{F}$ Med 1984; 311: 710-6.

13 Streptokinase in acute myocardial infarction. European cooperative study group for streptokinase treatment in acute myocardial infarction. $N$ Engl f Med 1979; 301: 797-802.

14 Aber CP, Bass NM, Berry CL, et al. Streptokinase in acute myocardial infarction: a controlled multicentre study in the United Kingdom. $\mathrm{Br}$ Med $\mathcal{F} 1976$; ii: 1100-4.

15 Australian multicentre trial of streptokinase in acute myocardial infarction. Med $\mathcal{F}$ Aust 1977; i: 553.
16 Anderson JL, Marshall HW, Askins JC, et al. A randomised trial of intravenous and intracoronary streptokinase in patients with acute myocardial infarction. Circulation 1984; 70: 606-18.

17 Spann JF, Sherry S, Carabello BA, et al. Coronary thrombolysis by intravenous streptokinase in acute myocardial infarction: acute and follow-up studies. $\mathrm{Am}$ f Cardiol 1984; 53: 655-61.

18 Schroder R. Intravenous short-term infusion of streptokinase in acute myocardial infarction. Int $\mathcal{F}$ Cardiol 1984; 5: 631-7.

19 Ganz W, Geft I, Shah PK, et al. Intravenous streptokinase in evolving acute myocardial infarction. $A m \mathcal{F}$ Cardiol 1984; 53: 1209-16.

20 Weinstein J. Treatment of myocardial infarction with intracoronary streptokinase: efficacy and safety data from 209 United States cases in the Hoechst-Roussel registry. Am Heart f 1982; 104: 894-8.

21 Alderman EL, Jutzy KR, Berte LE, et al. Randomised comparison of intravenous versus intracoronary streptokinase for myocardial infarction. Am $\mathcal{F}$ Cardiol 1984; 54: 14-9.

22 Mayer G, Story WE, Seco JE, Nocero MA, Shaskey DJ, Black MA. Intravenous streptokinase in acute myocardial infarction. Ann Emerg Med 1985; 14: 410-5.

23 Schroder R, Biamino G, Leitner E-RV, et al. Intravenous short-term infusion of streptokinase in acute myocardial infarction. Circulation 1983; 67: 536-47.

24 Shell W, Mickle DK, Swan HJC. Effects of nonsurgical myocardial reperfusion on plasma creatine kinase kinetics in man. Am Heart $\mathcal{F} 1983$; 106: 665-9.

25 Goldberg S, Greenspon AJ, Urban PL, et al. Reperfusion arrhythmia: a marker of restoration of antegrade flow during intracoronary thrombolysis for acute myocardial infarction. Am Heart $\mathcal{f}$ 1983; 105: 26-31.

26 Dewhurst NG, Muir Al. Comparative prognostic value of radionuclide ventriculography at rest and during exercise in 100 patients after first myocardial infarction. Br Heart f 1983; 49: 111-21.

27 Khaha F, Walton JA Jr, Brymer JF, et al. Intracoronary fibrinolytic therapy in acute myocardial infarction. Report of a prospective randomised trial. $N$ Engl f Med 1983; 308: 1305-11.

28 Harrison DG, Ferguson DW, Collins SM, et al. Rethrombosis after reperfusion with streptokinase: importance of geometry of residual lesions. Circulation 1984; 69: 991-9.

29 Mathey DG, Kuck K-H, Tilsner V, Krebber H-J, Bleifeld W. Non-surgical coronary artery recanalisation in acute transmural myocardial infarction. Circulation 1981; 63: 489-97.

30 Urban PL, Cowley M, Goldberg S, et al. Intracoronary thrombolysis in acute myocardial infarction: clinical course following successful myocardial reperfusion. Am Heart f 1984; 108: 873-8.

31 Messmer BJ, Merx W, Meyer J, Bardos R, Minale C, Effert $S$. New developments in medical-surgical treatment of acute myocardial infarction. Ann Thorac Surg 1983; 35: 70-6.

32 Gold HK, Leinbach RC, Palacios IF, et al. Coronary reocclusion after selective administration of streptokinase. Circulation 1983; 68:(suppl I): 50-4. 
33 Mathey DG, Rodewald G, Rentrop P, et al. Intracoronary streptokinase thrombolytic recanalisation and subsequent surgical bypass of remaining atherosclerotic stenosis in acute myocardial infarction: complementary combined approach effecting reduced infarct size, preventing reinfarction, and improving left ventricular function. Am Heart $\mathcal{F}$ 1981; 102: 1194-201.

34 Meyer J, Merx W, Schmitz $\mathrm{H}$, et al. Percutaneous transluminal coronary angioplasty immediately after intracoronary streptolysis of transmural myocardial infarction. Circulation 1982; 66: 905-13.

35 Been M, de Bono DP, Muir AL, Boulton FE, Hillis WS, Hornung R. Coronary thrombolysis with intravenous anisoylated plasminogen-streptokinase complex BRL 26921. Br Heart f 1985; 53: 253-9.

36 Verstraete $M$, Bory $M$, Collen D, et al. Randomised trial of intravenous recombinant tissue-type plasminogen activator versus intravenous streptokinase in acute myocardial infarction. Report from the European
Co-operative study group for recombinant tissue-type plasminogen activator. Lancet 1985; i: 842-7.

37 Van de Werf F, Bergmann SR, Fox KAA, et al. Coronary thrombolysis with intravenously administered human tissue-type plasminogen activator produced by recombinant DNA technology. Circulation 1984; 69: 605-10.

38 Laffel GL, Braunwald E. Thrombolytic therapy. A new strategy for the treatment of acute myocardial infarction. N Engl f Med 1984; 311: 770-6.

39 Relman AS. Intravenous thrombolysis in acute myocardial infarction. A progress report. $N$ Engl $f$ Med 1985; 312: 915-6.

40 Braunwald $\mathrm{E}$. The aggressive treatment of acute myocardial infarction. Circulation 1985; 71: 1087-92.

41 Verstraete M, Brower RW, Collen D, et al. Doubleblind randomised trial of intravenous tissue-type plasminogen activator versus placebo in acute myocardial infarction. Lancet 1985; ii: 965-9. 